\title{
MECHANICAL, MORPHOLOGICAL AND THERMAL CHARACTERIZATION OF HYBRID BAMBOO/GLASS FIBER REINFORCED POLYESTER COMPOSITES
}

\author{
Bino Prince Raja D. ${ }^{1}$, B. Stanly Jones Retnam ${ }^{2}$, Antony Samuel Prabu G. ${ }^{3}$ \\ and Alagu Sundaram A. ${ }^{4}$ \\ ${ }^{1}$ Department of Aeronautical, Noorul Islam Centre for Higher education, \\ Kumaracoil-629 18, Tamil Nadu, India \\ ${ }^{2}$ Department of Automobile, Noorul Islam Centre for Higher education, \\ Kumaracoil-629 18, Tamil Nadu, India \\ ${ }^{3}$ Department of Aeronautical, MVJ College of Engineering, \\ Bangalore-560067, Karnataka, India \\ ${ }^{4}$ Department of Aeronautical, Sha-Shib College of Engineering, \\ Bangalore-560067, Karnataka, India \\ *E-mail:binoaero87@gmail.com
}

\begin{abstract}
In the present research, synthesis and characterization of hybrid bamboo/glass fiber reinforced polyester (PE) matrix-based composites through compression moulding technique was fabricated and characterization is done. Seven different combinations of composite plates were prepared with the fiber alignment of $30^{\circ}$ and $60^{\circ}$ in a plain weaved mat form. Experimental results show that when hybrid fibers combined with polyester matrix, mechanical properties such as tensile strength, flexural strength, impact strength, hardness and water absorption tests of the matrix increases the superior specific strength and modulus but have a lower failure strain compared to other combinations and then pure bamboo or pure glass fiber possess decrease in strength compared to hybrid combinations. Thermal and Morphological investigation of the pure bamboo or pure glass fiber and hybrid fiber fiber-reinforced polyester composites have also been carried out. The results found show that application of these fibers as probable reinforcing materials in bio-based polymer composites.

Keywords: hybrid bamboo/glass, mechanical characterization, morphological and thermal analysis, polyester matrix
\end{abstract}

(c) RASĀYAN. All rights reserved

\section{INTRODUCTION}

Polymer Matrix Composite is either synthetic or natural fibre as reinforcement and polymer as a matrix. Synthetic fibres like carbon, aramid and glass are often used in aerospace and automobile structures due to low density, high stiffness and high strength. Due to these properties, synthetic fibers have serious drawbacks like health hazards, biodegradability, recyclability and initial processing cost etc. Natural fibres like banana, jute, coir, kenaf, sisal, hemp have the ability to replace the synthetic fibres due to environmental issues. In addition to that, natural fiber possesses light in weight, low cost, high flexibility, renewability, high specific strength, high toughness, easy and simple processing ${ }^{1-5}$. Natural fibres, have few dis-advantages stating as low strength and high-water absorption property. These limitations can be enhanced by using a technique called "hybridization technique". Hybrid composites are the composites, which have more than one reinforcement in a single matrix or multiple reinforcements with multiple matrix or single reinforcement with multiple matrix. This hybridization technique can increase the mechanical and thermal properties of single fibre polymer composites ${ }^{11}$. The high strength natural fibers used for reinforcing polymer composite materials is Jute and Bamboo fiber, gave the microscopic level for determining the strength of bamboo fiber ${ }^{6}$.

Rasayan J. Chem., 11(3), 990-998(2018)

http://dx.doi.org/10.31788/RJC.2018.1133048

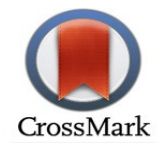


In this paper, mechanical properties, thermal properties, water absorption property and morphological property of hybrid bamboo/glass fibre reinforced polyester composite are discussed.

\section{Preparation of Material}

\section{EXPERIMENTAL}

A diameter of $10 \mu \mathrm{m}$ and $6 \mu \mathrm{m}$ were chosen as the fibre diameter for bamboo and glass fibre respectively. Silane was introduced for the chemical reaction, also to enhance and improve the properties of the bamboo fibre. Polyester resin is chosen as the matrix material for this project. Cobalt naphthenate and MEKP were used in the form oxidizer and catalyst in order.

\section{Fabrication of Composites}

The Compression Moulding process was made use for the composite plate preparation. All the composite plates were fabricated in the molding box size of $200 \times 150 \times 10 \mathrm{~mm}$ in wood. The bamboo fibre woven was positioned and then the required amount of polyester resin was drizzled over it and the same process continued for hybrid composite plate preparation also. Primarily, the fibre was compressed to remove the air bubbles and plates were prepared by means of a hydraulic hot press machine ${ }^{9}$. The polymer was made to preheat at a certain temperature for a specified time to soften them. Hence it obtains the desired shape.

The number of plates was fixed to seven for the different composite sample. Different composite samples with varying stacking order of laminas were prepared as shown in the table. Seven different kinds of plates were built and shown in Fig.-1.

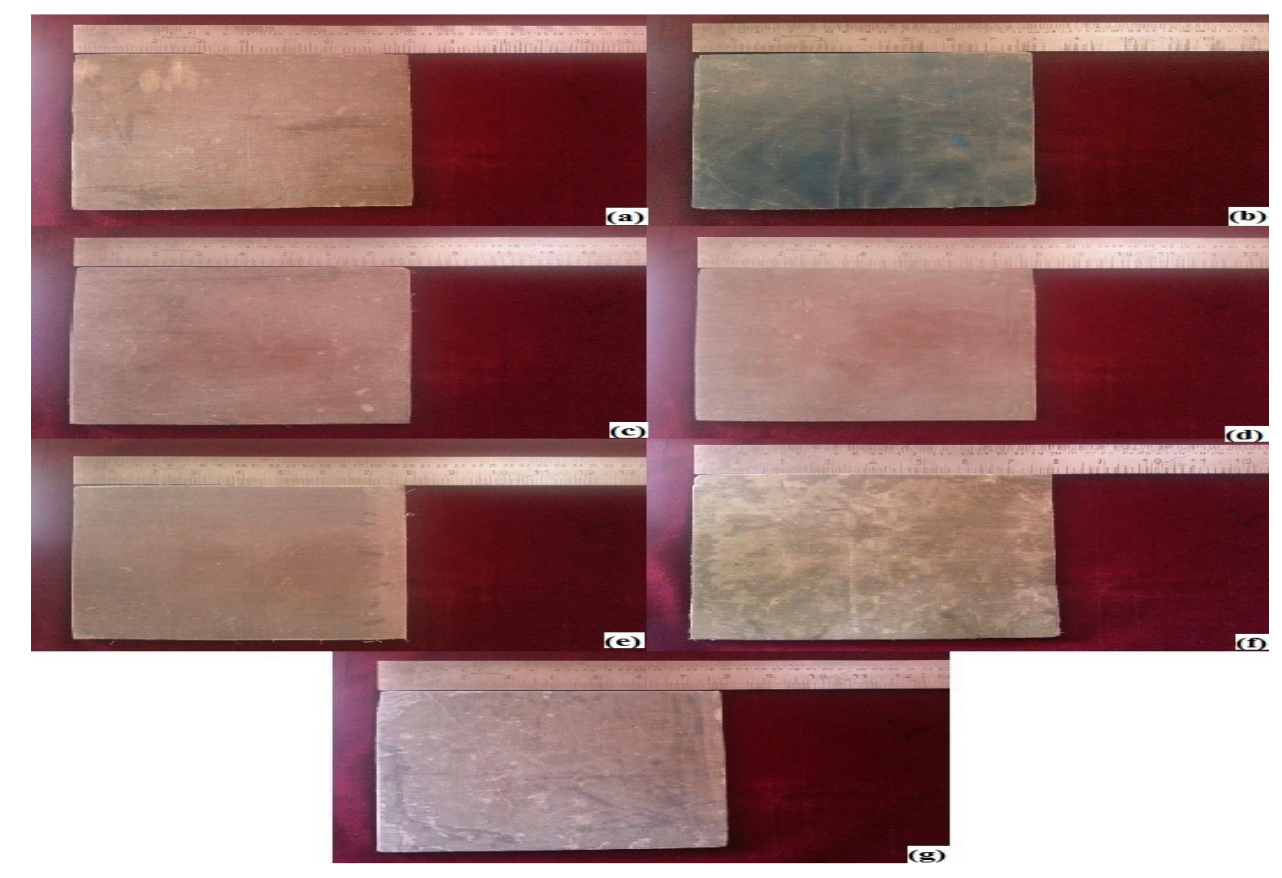

Fig.-1: Composite Plates

\section{Material Characterization of Composites}

The milling cutter was used to cut the plates into specimens as per ASTM standards. For attaining prerequisite orientations, the specimens were arranged as templates from the GI sheets, proceeding the $30^{\circ}$ and $60^{\circ}$ orientation. Finally, the plates made are cut into the definite angle.

The specimens for the tensile test was prepared according to the ASTM D638 standard. The tensile strength of the bamboo, hybrid bamboo/glass and bamboo/micro/Nano powder composites were prepared with a different volume percentage and of orientations $30^{\circ}$ and $60^{\circ}$ respectively, in accordance with the 
RASĀYAN J. Chem.

Vol. 11 | No. 3 |990 - 998 | July - September | 2018

ASTM D638 procedure. The specimens were cut in the ASTM D 638 standard, whereas samples were secured in the UTM with the specifications of $5 \mathrm{~mm}$ gauge length and $2 \mathrm{~mm} / \mathrm{min}$ crosshead speeds.

The specimen for the flexural test was prepared according to the ASTM D790 standard ${ }^{7}$. The flexural strength of the bamboo, hybrid bamboo/glass and bamboo/micro/Nano powder composites were prepared with a different volume percentage and of orientations $30^{\circ}$ and $60^{\circ}$ respectively, in accordance with the ASTM D790 procedure. The specimens were cut in the ASTM D 790 standard, whereas samples were secured in the UTM with the specifications and the speed of test was controlled as $2 \mathrm{~mm} / \mathrm{min}$ and the span-to-depth ratio was ranged as 16: 1 .

The specimens for the impact test was prepared according to the ASTM D6110 standard. The impact strength of the bamboo, hybrid bamboo/glass and bamboo/micro/Nano powder composites were prepared with different volume percentage and of orientations $30^{\circ}$ and $60^{\circ}$ respectively. The charpy testing machine is used to measure the impact strength, in accordance with the ASTM D6110 procedure. The energy obtained from the results is divided upon the area of the cross-section of the specimen to calculate the values of the fracture occurred in the specimens.

Table-1: Combination of Polyester Resin, Bamboo Fiber and Glass Fiber

\begin{tabular}{|c|c|c|c|c|}
\hline S. No. & Specimens & Combinations & $\begin{array}{c}\text { Volume } \\
(\%)\end{array}$ & $\begin{array}{c}\text { Weight } \\
(\mathrm{gm})\end{array}$ \\
\hline \multirow[t]{2}{*}{1} & \multirow[t]{2}{*}{$\bar{A}$} & Polyester resin & 70 & 1080 \\
\hline & & Bamboo & 30 & 450 \\
\hline \multirow[t]{2}{*}{2} & \multirow[t]{2}{*}{ B } & Polyester resin & 75 & 1150 \\
\hline & & E-glass fiber & 25 & 425 \\
\hline \multirow[t]{3}{*}{3} & \multirow[t]{3}{*}{$\mathrm{C}$} & Polyester resin & 70 & 1100 \\
\hline & & Bamboo & 15 & 200 \\
\hline & & E-Glass fibre & 15 & 200 \\
\hline \multirow[t]{3}{*}{4} & \multirow[t]{3}{*}{$\mathrm{D}$} & Polyester resin & 70 & 1125 \\
\hline & & Bamboo & 10 & 150 \\
\hline & & E-Glass & 20 & 300 \\
\hline \multirow[t]{3}{*}{5} & \multirow[t]{3}{*}{$\mathrm{E}$} & Polyester resin & 70 & 1125 \\
\hline & & Bamboo fibre & 20 & 300 \\
\hline & & E-Glass & 10 & 150 \\
\hline \multirow[t]{3}{*}{6} & \multirow[t]{3}{*}{$\mathrm{F}$} & Polyester resin & 70 & 1125 \\
\hline & & Bamboo & 27 & 280 \\
\hline & & $\begin{array}{l}\text { Coconut shell } \\
\text { powder in the } \\
\text { micro size }\end{array}$ & 3 & 12 \\
\hline \multirow[t]{3}{*}{7} & \multirow[t]{3}{*}{ G } & Polyester resin & 70 & 1125 \\
\hline & & Bamboo & 27 & 280 \\
\hline & & $\begin{array}{l}\text { Coconut shell } \\
\text { powder in Nano } \\
\text { size }\end{array}$ & 3 & 10 \\
\hline
\end{tabular}

The specimens for the tensile test was prepared according to the ASTM D785 standard. The tensile strength of the bamboo, hybrid bamboo/glass and bamboo/micro/Nano powder composites were prepared with a different volume percentage and of orientations $30^{\circ}$ and $60^{\circ}$ respectively, in accordance with the ASTM D785 procedure. Nevertheless, the Specimens dimensions of a standard sample of thickness $6 \cdot 4$ $\mathrm{mm}$ were engraved. The hardness value was calculated by imparting the load for a period of $15 \mathrm{sec}$.

Water absorption specimens were prepared as per ASTM D 5229. Water absorption test is used to measure the amount of water absorbed under specified conditions. The weight of each specimen was taken before immersing in water (initial weight). Specimens were then immersed in rain water at room 
temperature of about $32^{\circ} \mathrm{C}$. After a period of about 24 hours' time period, the samples were taken out, then wiped with tissue paper to remove the moisture, using an electronic weighing machine accurate to $10^{-4}$. The readings were taken for a time period of 21 days for a period of 24 hours and the readings were calculated. The moisture content, $\mathrm{M}(\mathrm{t})$ absorbed by each specimen is calculated from its weight before, $\mathrm{w}$ (0) and after, w (t) absorption by using the following equation,

$$
M(t)=100\left(\frac{W_{t}-W_{0}}{W_{0}}\right)
$$

Thermo gravimetric analysis was carried out using a Mettler Toledo SDTA 851 analyzer. The samples weighing between 5.80-9.02 mg were placed in ceramic crucibles, while the tests were carried out in a nitrogen atmosphere. The heating rate of the samples was $20^{\circ} \mathrm{C}$ min- 1 .

To investigate the fibre Matrix Morphology, SEM analysis is implemented. The insinuation of the bonding between the matrix and reinforcement is one of the main purposes of this test. Magnification of $3 \mathrm{~mm}$ is considered for the experimental investigation.

\section{RESULTS AND DISCUSSION}

\section{Tensile Strength}

Figure-2 and 3 show the Specimen Vs UTS (ultimate tensile strength) of the pure bamboo, hybrid bamboo/glass and bamboo/micro/Nano powder composites corresponding to fibre orientation of $\pm 30^{\circ}$ and $\pm 60^{\circ}$. The graph was drawn using MATLAB. Figure- 2 implies that Specimen G exhibits a significant rise in tensile strength, in comparison with other combinations and Figure 3 implies that Specimen $G$ exhibits a significant rise in tensile strength, in comparison with other combinations.

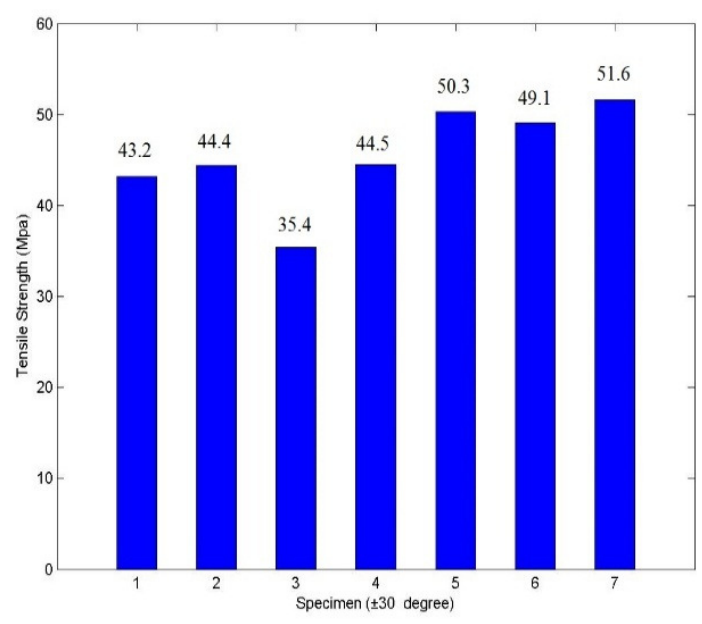

Fig.-2: Specimen vs Tensile Strength $\left( \pm 30^{\circ}\right)$

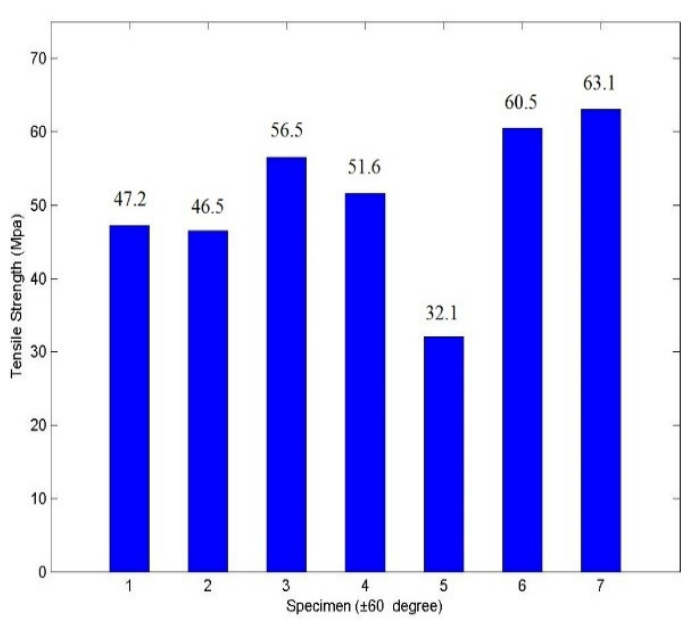

Fig.-3: Specimen vs Tensile Strength $\left( \pm 60^{\circ}\right)$

\section{Flexural Strength}

Figure- 4 and 5 indicate the Specimen Vs. Flexural strength of pure bamboo, hybrid bamboo/glass and bamboo/micro/Nano powder composites corresponding to fiber orientation of $\pm 30^{\circ}$ and $\pm 60^{\circ}$. The graph was drawn using MATLAB. Figure-4 implies that Specimen $G$ exhibits a significant rise in flexural strength, in comparison with other combinations and Fig.-5 implies that Specimen B exhibits a significant rise in tensile strength, in comparison with other combinations.

\section{Impact Strength}

Figure-6 and 7 show the Specimen Vs. Impact strength of the pure bamboo, hybrid bamboo/glass and bamboo/micro/Nano powder composites corresponding to fiber orientation of $\pm 30^{\circ}$ and $\pm 60^{\circ}$. The graph was drawn using MATLAB. Figure-6 implies that Specimen D exhibits a significant rise in flexural 
strength, in comparison with other combinations and Fig.-7 implies that Specimen D exhibits a significant rise in tensile strength, in comparison with other combinations.

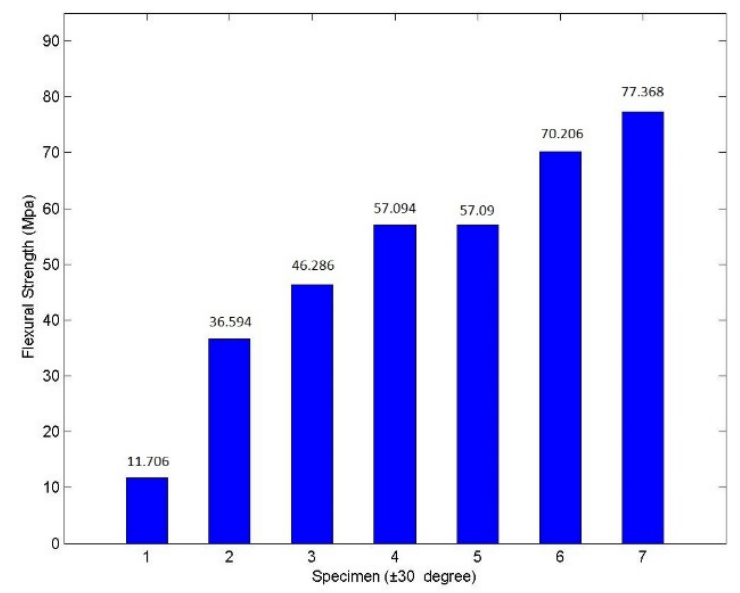

Fig.-4: Specimen vs Flexural Strength $\left( \pm 30^{\circ}\right)$

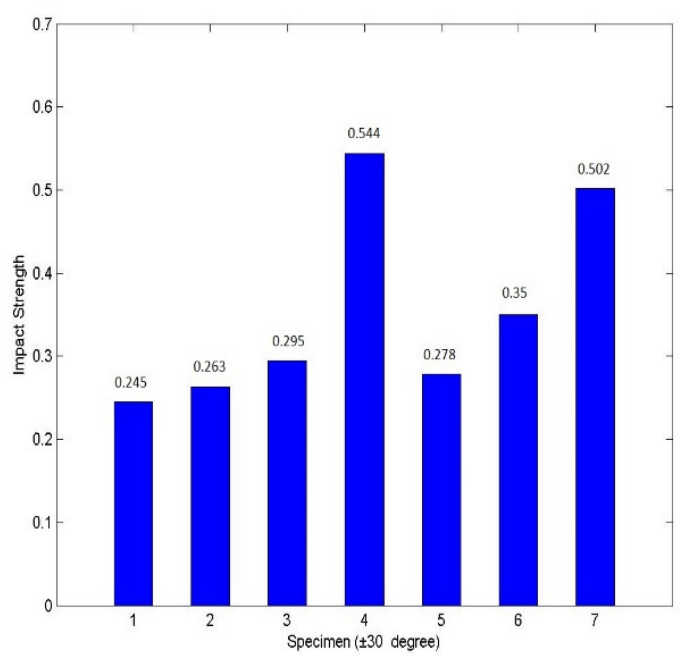

Fig.-6: Specimen vs Impact Strength $\left( \pm 30^{\circ}\right)$

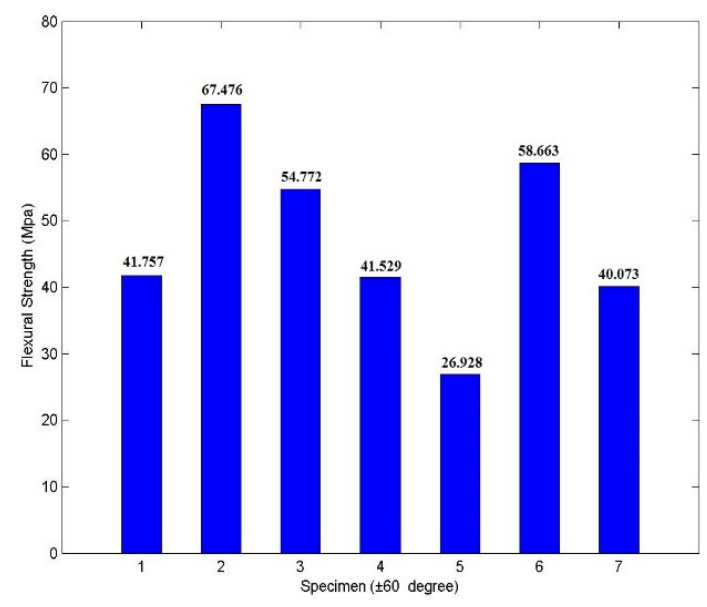

Fig.-5: Specimen vs Flexural Strength $\left( \pm 60^{\circ}\right)$

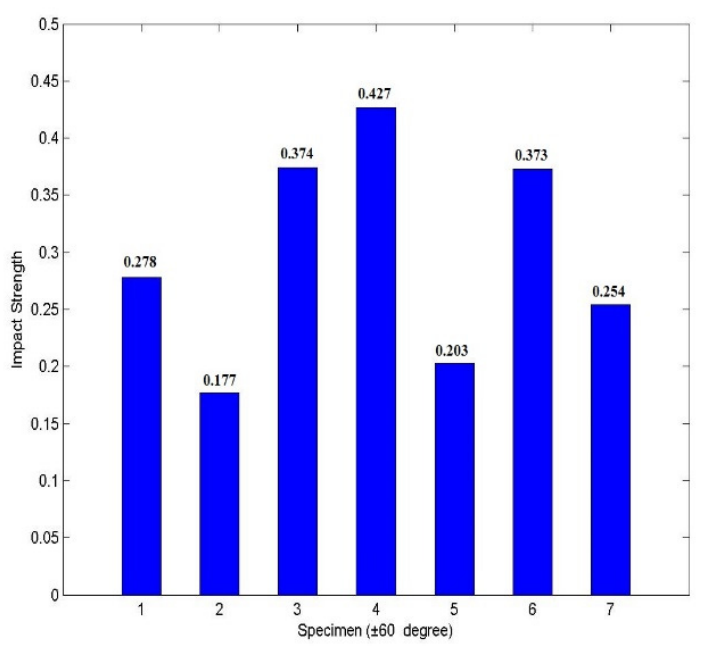

Fig.-7: Specimen vs Impact Strength $\left( \pm 60^{\circ}\right)$

\section{Hardness Number}

Figure-8 shows the Specimen Vs. Hardness Number of the pure bamboo, hybrid bamboo/glass and bamboo/micro/Nano powder composites. The graph was drawn using MATLAB. Figure-8 implies that Specimen E exhibits a significant rise in hardness number, in comparison with other combinations.

\section{Water Absorption}

Figure-9 showed very low moisture absorption for all the specimens as the fibers were closely packed by the matrix materials. But the hybrid fiber exhibited very low moisture absorption property due to the availability of glass fiber.

This was followed by Nano and micro coconut shell filler added FRP specimens as the fine gaps in the specimens were packed by the fine fillers which prevented from the formation of voids in the matrix. This improved the water absorption property of the materials. Hence, Specimen A has comparatively more moisture when compared to other specimens. 
RASĀYAN $J$. Chem.

Vol. 11 | No. 3 |990 - 998 | July - September | 2018
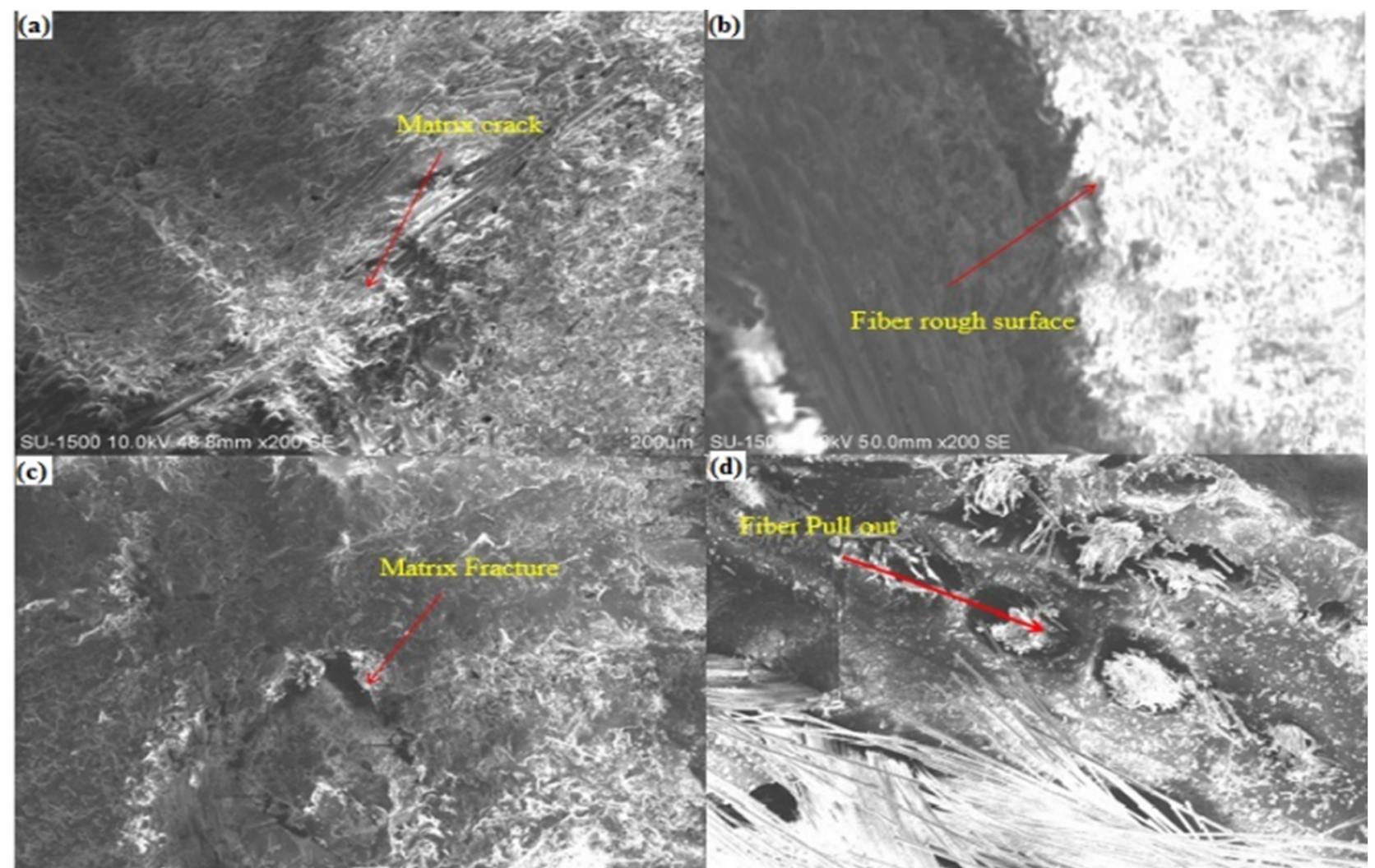

(d)
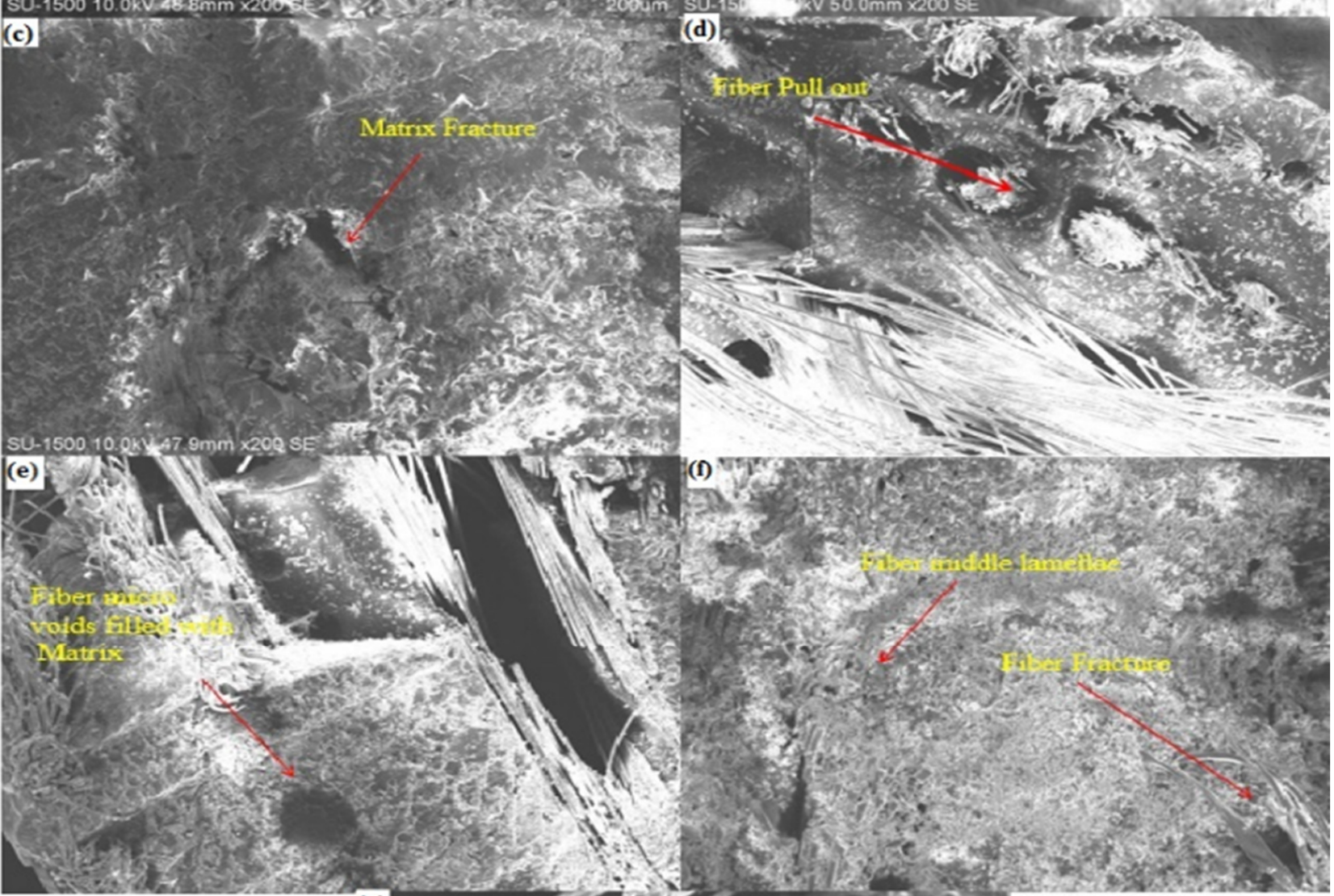

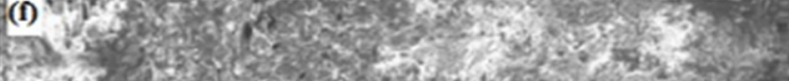

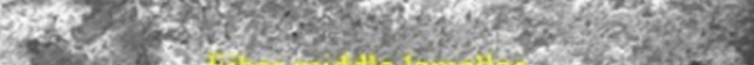

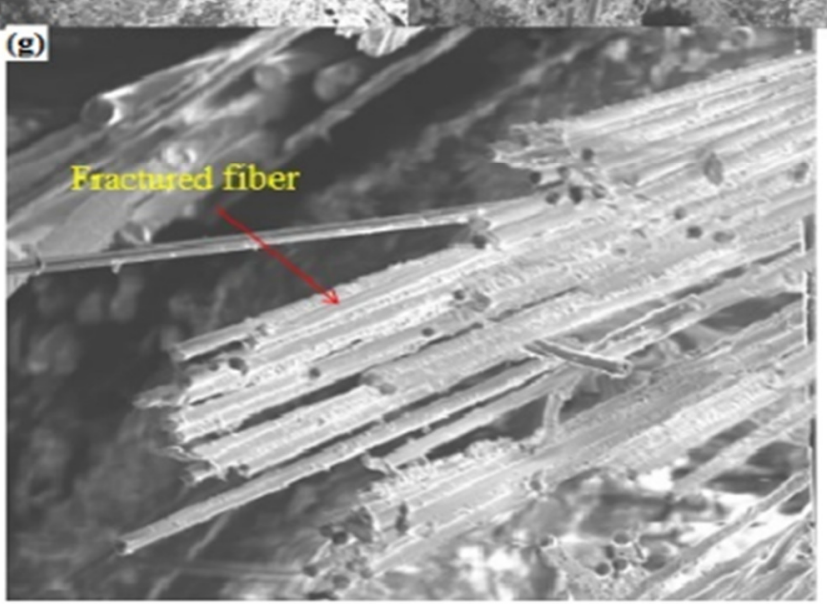

Fig.-10: SEM Image of all 7 Specimens with $200 \mu \mathrm{m}$ Magnification 
RASĀYAN J. Chem.

Vol. 11 | No. 3 |990 - 998 | July - September | 2018
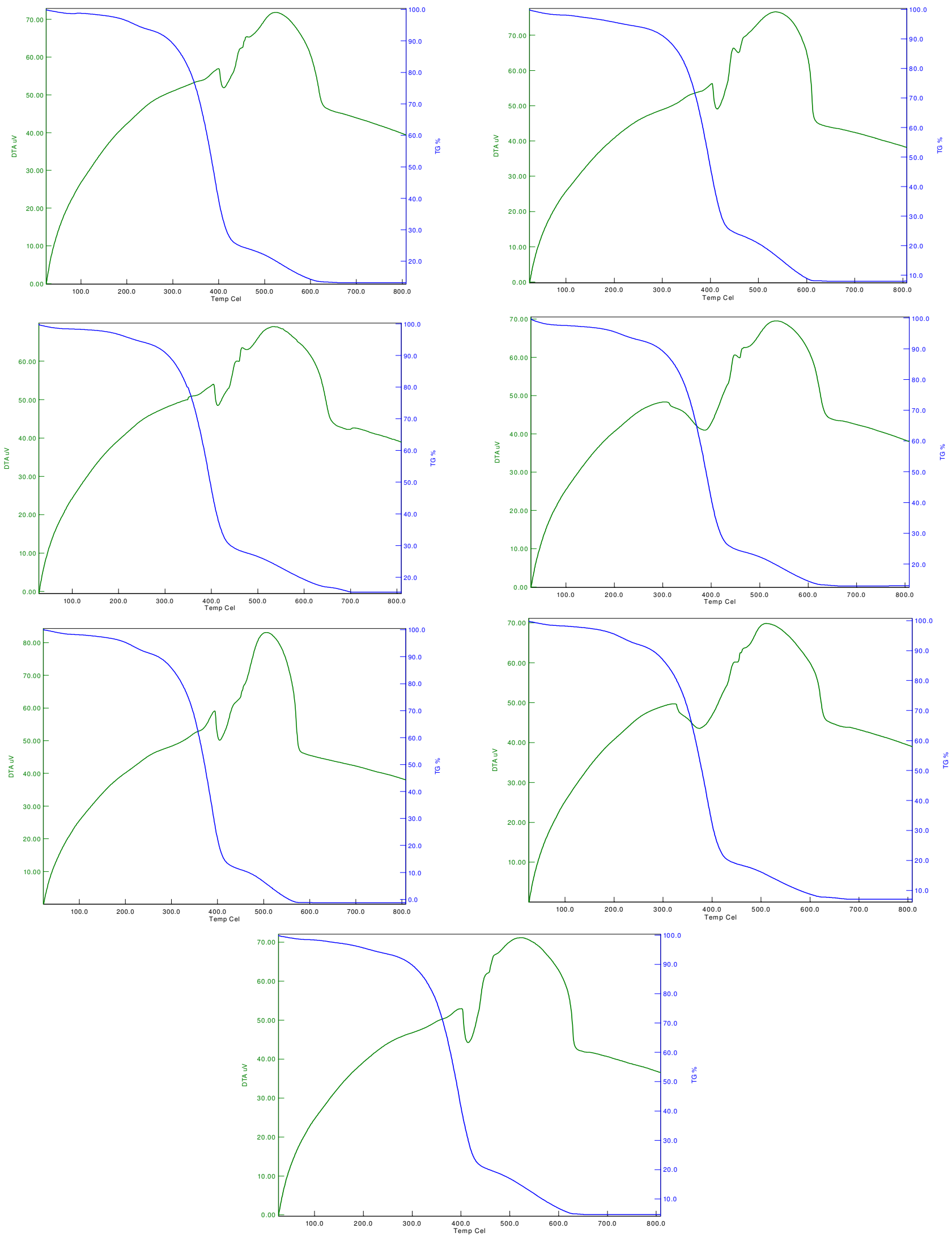

Fig.-11: TGA Analysis Graph of All the Samples 


\section{Morphological Analysis}

From Fig.-10, the surface morphology of the bamboo/glass fibres bonding with polyester resin in the tensile specimens after breakage was examined by the implementation of SEM analysis. The cross-section of the composites of different combination corresponding to orientation is shown in Fig.-10(a-g) with 200 $\mu \mathrm{m}$ magnification. It was apparent that hybrid fibre bears a high degree of intensity and compactness than the solitary fibre arrangement. The polymer composite manufacturing with the rough-surfaced fibre bonded strongly with the matrix was disclosed explicitly.

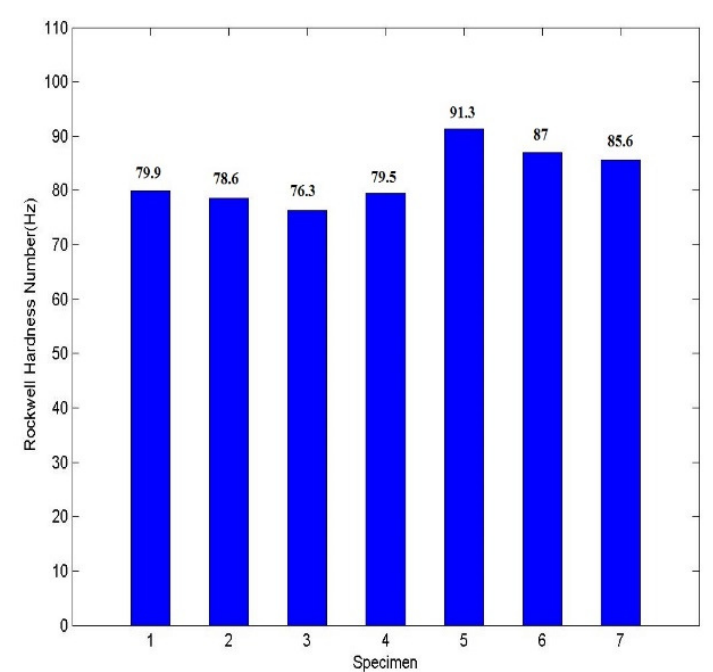

Fig.-8: Specimen vs Hardness Number

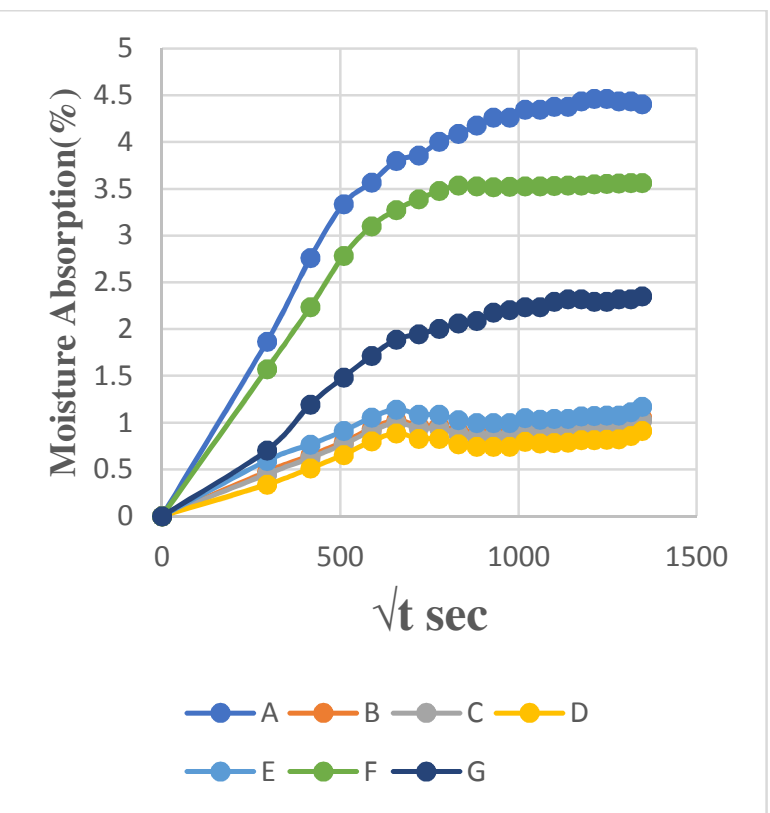

Fig.-9: Weight Gains in \% Vs Vtime in sec

\section{Thermal Analysis}

With respect to this analysis, the Thermo gravimetric (TGA) curves were utilized to decide the thermal degradation and thermal stability of every material. The TG analysis of neat high impact polyester, bamboo/glass fibre and their composites are mentioned in Fig.-11. The thermal decomposition of each sample occurred in a customized temperature scope of $25^{\circ} \mathrm{C}$ to $800^{\circ} \mathrm{C}$.

\section{CONCLUSION}

- The composite of combination indicated as G (Bamboo fibre with coconut shell powder in Nano size) with $\pm 60^{\circ}$ orientation produced the maximum tensile strength of $63.1 \mathrm{MPa}$ which is higher than several other orientations of $0^{\circ} / 90^{\circ}, 30^{\circ}$ and $\pm 45^{\circ}$.

- The composite of combination indicated as G (Bamboo fibre with coconut shell powder in Nano size) with $\pm 30^{\circ}$ orientation produced the maximum flexural strength of $77.368 \mathrm{MPa}$ which was higher when compared with other orientations of $0^{\circ} / 90^{\circ}, 60^{\circ}$ and $\pm 45^{\circ}$.

- The highest impact strength of $0.544 \mathrm{~J} / \mathrm{mm}^{2}$ was indicated in Specimen D (hybrid bamboo/glass fibre), yet altogether it was greater than the other orientations $0^{\circ} / 90^{\circ}, 60^{\circ}$ and $\pm 45^{\circ}$.

- The highest hardness number of $91.3 H_{\mathrm{R}}$ was renowned for combination indicated as $\mathrm{E}$ specimen, which is almost had the highest hardness number compared to other combinations.

- SEM investigation indicates the specimen $F$ and $G$ possess strong bonding of the bamboo/Nano powder PMC of diverse combination than the other combinations.

- Thermal analysis indicates that Specimen D proves its stability to withstand polymerization temperature.

Overall the characterization results confirm the chances of using this fiber for fabrication of sustainable FRP composite and its peak applications in the aerospace industry. 
RASĀYAN J. Chem.

Vol. 11 | No. 3 | 990 - 998 | July - September | 2018

\section{REFERENCES}

1. G. Ramanan, J. Edwin Raja Dhas, M. Ramachandran and G. Diju Samuel, Rasayan Journal of Chemistry, 10,375(2017), DOI: 10.7324/RJC.2017.1021663

2. A. K. Darwins, M. Satheesh and G. Ramanan, Rasayan Journal of Chemistry, 11,365 (2018), DOI: 10.7324/RJC.2018.1112030

3. G. Zak, M. Haberer, C. B. Park and B. Benhabib et al., Rapid Pro-totyping J., 6, 107(2000), DOI: $10.1115 / 1.1581888$

4. M. F. Yu, B. S. Files, S. Arepalli and R. S. Ruoff, Phys. Rev. Lett, 84, 5552(2000), DOI: 10.1103/PhysRevLett.84.5552

5. B. Stanly Jones Retnam, M. Sivapragash and P. Pradeep, Bulletin of Material Science, 5, 37(2014), DOI: 10.1007/s12034-014-0045-y

6. D. Bino Prince Raja, Stanly Jones Retnam, Mohini Shukla, International Journal of Mechanical Engineering and Technology,8,10(2017)

7. R. Varatharajan, S. K. Malhotra, L. Vijayaraghavan and R. Krishnamurthy, Materials Science and Engineering: B, 2, 132(2006), DOI: 10.1016/j.mseb.2006.02.010

8. S. Pardo, D. Baptiste, F. Décobert, J. Fitoussi and R. Joannic et al.,Composite Science and Technology, 4, 64(2002)

9. M. Skrifvars, T. Mackin and B. Skagernerg et al., Polymer Testing, 17, 245(1998)

10. M. K. Gupta, R. K. Srivastava, Mater Today: Proceed, 8, 24(2015)

11. M. S. Huda, L. T. Drzal, A. K. Mohanty, M. Misra, Compos Sci Technol., 5,66(2006), DOI: 10.1016/j.compscitech.2005.10.015

12. Y. Lo Tommy, H. Z. Cui, P.W.C. Tang, and H.C. Leun, Construction and Building Mater., 22, 42 (2008)

13. S. Kumar, M. Chakraborty, V. S. Sarma, B. S. Murty, Wear, 265(1-2), 134(2008).

14. N. Barekar, S. Tzamtzis, B. K. Dhindaw, J. Patel, N. Hari Babu, Z. Fan, Journal of Materials Engineering, 18, 1230 (2009), DOI: 10.1007/s11665-009-9362-5

15. K. Shorowordi, T. Laoui and L. Froyen, J. Mater Processing Technol, 142, 738 (2003).

16. Maria Marinescua, Ana Emandia and Octavian G. Duliub, Vibrational Spectroscopy, 73, 127 (2014)

17. Zhixiong Zhu, Jian Han, Chong Gao, Mao Liu, Jianwei Song, Zhiwei Wang and Huijun Li, Materials Science and Engineering: A, 681, 65 (2017), DOI:10.1016/j.msea.2016.10.108

18. V. Ganesh, C. K. Lee and M. Gupta, Materials Science and Engineering A, 333, 193 (2002), DOI: 10.1016/S0921-5093(01)01831-7

19. C. S. Ramesh, Abrar Ahamed, and R. Keshavamurthy, Materials and Design, 31, 2230 (2010)

20. Soumitra Kumar Dinda, Md. BasiruddinSk, Gour Gopal Roy, Prakash Srirangam, Materials Science and Engineering: A, 677, 182 (2016).

21. Rabindra Behera, S. Das, D. Chatterjee and G. Sutradhar, J. of Minerals and Materials Charac. And Engineering. 10, 923 (2011), DOI: 10.4236/jmmce.2011.1010072

22. Chennakesava Reddy and Essa Zitoun, Ind. J. of Sci. and Technology. 3, 1 (2010)

23. I. Dinaharan, N. Murugan and S. Parameswaran, Materials Science and Engineering A, 528, 5733 (2011), DOI: 10.1016/j.msea.2011.04.03

24. J. Jeykrishnan, B. Vijaya Ramnath, X. Hervin Savariraj, R.David Prakash, V. R. Dhinesh Rajan and D. Dinesh Kumar, Indian Journal of Science and Technology, 9, 1(2016)

[RJC-3048/2018] 